\title{
Is Repetitive Workload a Risk Factor for Upper Extremity Musculoskeletal Disorders in Surgical Device Mechanics? A Cross-Sectional Analysis
}

\author{
Oliver Lotter ${ }^{1, * \mathbb{D}}$, Tobias Lieb ${ }^{2}$, Viktor Breul ${ }^{3}$ and Jochen Molsner ${ }^{4}$ \\ 1 Department of Plastic, Aesthetic, Hand and Reconstructive Surgery, Academic District Hospital, \\ Zeppelinstrasse 21, 78532 Tuttlingen, Germany \\ 2 Office for Occupational and Hand Therapy, Neuhauser Strasse 85, 78532 Tuttlingen, Germany; \\ tobiaslieb@gmx.de \\ 3 Department of Medical Scientific Affairs, Aesculap AG, Am Aesculap Platz, 78532 Tuttlingen, Germany; \\ viktor.breul@aesculap.de \\ 4 IAS-Group for Occupational Health Management, Koenigstrasse 6, 78532 Tuttlingen, Germany; \\ Jochen.Molsner@ias-gruppe.de \\ * Correspondence: oliver.lotter@googlemail.com; Tel.: +49-7424-950-4491
}

Received: 14 January 2020; Accepted: 20 February 2020; Published: 21 February 2020

\begin{abstract}
To assess the prevalence of upper extremity work-related musculoskeletal disorders (WMSDs) among surgical device mechanics compared to a control group, a total of 70 employees were included and assigned to three occupational groups (grinders, packers, and control). Personal factors, work exposure, manual skill, and complaints were assessed by two self-administered questionnaires and an industry test. WMSDs were diagnosed in a standardised clinical examination. The two-one-sided $t$-tests (TOST) procedure was used to test the clinical equivalence of the respective grinding and packaging groups vs. the control group in terms of the Disabilities of the Arm, Shoulder and Hand (DASH) score. Thirty-nine study participants (56\%) experienced at least one WMSD at the elbow, forearm, and/or wrist, mainly with signs of epicondylitis and nerve entrapment at the medial elbow. The risk of grinders developing upper extremity WMSD was about 2.5-times higher and packers had an 8.6-fold higher risk of a clinically relevant DASH $>29$ compared to the control group. However, these differences were not statistically significant. The groups were also proven to be clinically equivalent in terms of DASH score. Surgical device mechanics do not seem to have worse DASH values or be at higher risk of upper limb WMSDs compared to a control group. This is the first study to analyse and compare different workplaces in this industry that are also common in other industries.
\end{abstract}

Keywords: work-related musculoskeletal disorders (WMSDs); upper extremity; repetitive work; surgical device mechanics; DASH score; Purdue Pegboard Test

\section{Introduction}

Work-related musculoskeletal disorders (WMSDs) are pathologies in which the work environment and performance of work contribute significantly to the condition and/or the condition is made worse or persists longer due to work [1]. These disorders develop in the musculoskeletal system over a prolonged period of time and may limit activities in the professional environment or non-professional activities [2,3]. WMSDs describe a wide range of inflammatory and degenerative diseases that result in pain and functional impairment [4]. They are a significant occupational health problem among industrial and clerical workers with a significant medical, economic, and social impact in terms of absence due to sickness, cost of medical care, lost production, and personal suffering [5]. However, 
determining the true burden of morbidity associated with work activities still remains difficult within current surveillance and medical insurance systems [6]

Upper extremity pathologies related to work were first described in the 18th century by the Italian doctor and philosopher Bernardini Ramazzini, the father of occupational medicine. Today, the overall prevalence of upper extremity WMSDs ranges from $4 \%$ to $20 \%$ [7]. It has been estimated that the total cost of these disorders is between $0.5 \%$ and $2.0 \%$ of the gross national product in Scandinavian countries [8].

A PubMed search using the search terms "musculoskeletal disorder" AND "work" AND "upper extremity" (date of search: 12 July 2019) returned 1504 hits; from these hits 262 articles were shortlisted. Of 178/262 (68\%) original research articles found, 60/178 (34\%) publications contained a clinical examination of the test subjects with or without structured questionnaires/interviews. Of these, 50 were publications with a cross-sectional study design, but only 11 articles contained a control group.

Sorgaz described a repetitive strain injury model according to which highly frequent repetitive movements cause microlesions that accumulate in the affected musculoskeletal structures and eventually cause symptoms [9]. Epidemiological investigation indicates that adverse ergonomic exposures, vibration, forceful exertions, awkward postures, distribution of recovery periods, and duration of exposure are risk factors for developing WMSDs in the upper extremity [10,11]. However, there is conflicting information regarding monotonous and repetitive movements [12-15]. A multifactorial genesis of symptoms, including environmental, sociocultural, and personal characteristics, seems to be the leading hypothesis nowadays [16,17].

Upper extremity WMSDs have been shown to be related to numerous occupational situations and specific industries [18]. The medical device industry has not yet been analysed in this context. The objective of this study was to evaluate the prevalence of upper extremity WMSDs among surgical device mechanics compared to a control group. We hypothesised that disorders would not differ to a clinically relevant extent between surgical device mechanics performing specific repetitive work with and without forceful exertions compared to a control group.

\section{Materials and Methods}

\subsection{Study Population: Subjects, Design, and Procedure}

This study was conducted at the headquarters and main production site of Aesculap AG, Tuttlingen, Germany, which has approximately 3500 workers and employees. It is the world leading manufacturer of surgical instruments situated in a local area with more than 400 medical technology companies of varying sizes. Following an analysis of the workstations and work content, we defined three different study groups: group I = grinding and polishing characterised by repetitive and forceful exertions (subsequently referred to as "grinding"); group II = inspection and packaging characterised by repetitive exertions without force (subsequently referred to as "packaging"); and group III = all other white-collar and blue-collar employees working in manufacturing, warehouse, and office, representing a cross-section of the company not including groups I and II (but including other surgical device mechanics whose work does not include the activities performed by the first two groups) as a control group (hereinafter referred to as "control"). A detailed description of the job tasks is listed in Table 1. Representative pictures of the workstations are shown in Figures 1 and 2. 
Table 1. Description of job tasks.

\begin{tabular}{ccc}
\hline Work contents & Grinding & Packaging \\
\hline Grinding and polishing of workpieces & $\begin{array}{c}\text { Pre- and post-processing (acceptance } \\
\text { of orders, control, final cleaning) }\end{array}$ & $\begin{array}{c}\text { Pre- and post-processing } \\
\text { (acceptance of orders, inspection) }\end{array}$ \\
\hline Main activity time proportion & $60 \%-80 \%$ & $80 \%-90 \%$ \\
\hline Working position & Sitting & $\begin{array}{c}\text { Both sitting and standing } \\
\text { depending on the workstation }\end{array}$ \\
\hline Weight of product/packaging & $\begin{array}{c}1 \mathrm{~kg} \text {, on average significantly less, } \\
\text { higher total load }\end{array}$ & $\begin{array}{c}10 \mathrm{~kg} \text {, on average significantly less, } \\
\text { lower total load }\end{array}$ \\
\hline Use of hands & $\begin{array}{c}\text { The leading hand is not changed } \\
\text { (one-sided static load) }\end{array}$ & $\begin{array}{c}\text { Both hands (all planes of motion } \\
\text { with high ROM) }\end{array}$ \\
\hline Range of motion & Low & High \\
\hline Load & Medium-heavy & Light to medium-heavy \\
\hline
\end{tabular}

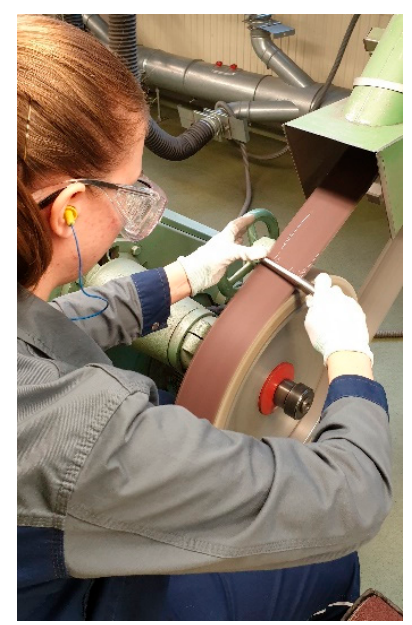

Figure 1. Workplace grinding.

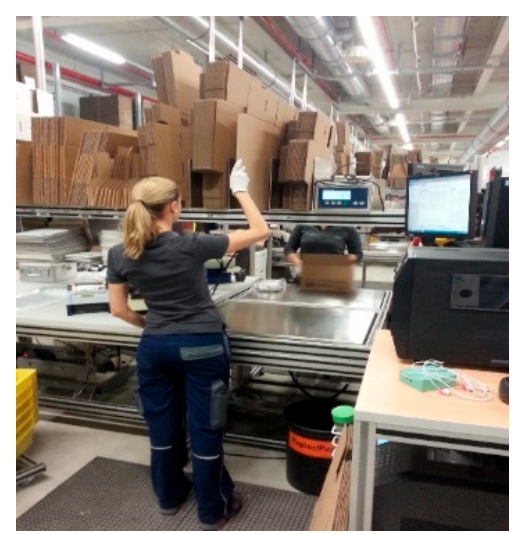

Figure 2. Workplace packaging.

Control: The control group represents a cross-section of the company's working population. All workplaces at the company were included, from light office work to heavy work with high physical strain. 
The study was approved by the Ethics Committee of the State Medical Council of Baden-Wuerttemberg, Jahnstrasse 40, 70,597 Stuttgart, Germany (project number F-2017-005). Random samples of active white-collar and blue-collar workers from the targeted groups were taken via randomisation lists between September 2017 and March 2018 and this sample population was asked to fill in two self-administered questionnaires after having agreed to enter the study and signed the informed consent form. No incentives were offered. The first standardised questionnaire obtained information about exclusion criteria (see below), demographic, and personal data, such as sex, handedness, secondary occupation, sporting and physical hobbies (categorical parameters), age, height and weight (body mass index), volume of employment, and years of service (continuous parameters). Current subjective complaints in the upper extremities (i.e., symptoms) were also recorded in this questionnaire. The validated Disabilities of the Arm, Shoulder and Hand (DASH) outcome measure was used as a second questionnaire $[19,20]$. The results of this 30-item questionnaire were used to calculate a scale score ranging from 0 (no disability) to 100 (most severe disability), known as the disability/symptom score. In addition, data was also collected using two optional modules intended to measure symptoms and function in athletes, performing artists, and other workers, whose jobs require a high degree of physical performance (sport/music and work scores).

The following exclusion criteria were applied in this study:

- Age $<18$ or $>65$ years.

- Employment in the respective workplace for less than 5 years.

- Currently on sick leave.

- Absence from work due to upper extremity pain for more than 2 weeks within the last 3 months.

- Cervical spine syndrome or herniated intervertebral disc.

- Shoulder pain radiating into the forearm.

- Debilitating congenital malformation of the upper extremity.

- Rheumatoid conditions including fibromyalgia.

- Previous upper extremity surgery due to nerve entrapment syndrome(s) and/or chronic musculoskeletal disorders, such as tennis elbow, golfer's elbow, tenosynovitis of the flexor and/or extensor tendons, including trigger finger and de Quervain's disease.

- More than three unanswered items in the DASH disability/symptom questionnaire.

\subsection{Objectives}

We applied the DASH to measure physical function and symptoms in patients with one or more musculoskeletal disorders in the upper limb [21]. We chose an equivalence design with a margin of 15 points to assess the clinically detectable differences between different occupational groups [22]. We also collected data on secondary endpoints in order to evaluate the outcome of the exposure (see clinical data and Purdue Pegboard Test).

\subsection{Clinical Data}

The participants were invited for a structured physical examination of the elbow, forearm, wrist, and hand. It consisted of active range of motion (ROM) manoeuvres of the wrist (as measured in 3 planes using the neutral zero method), grip strength by Jamar dynamometer ( 3 measurements per side), pain on a visual analogue scale (VAS) at rest and under strain, as well as a search for tender points for tenosynovitis. The examiner decided the diagnoses based on a standard set of criteria for pathognomonic clinical signs specific to upper extremity pathologies as proposed by Waris et al. [23]. These included pain on the radial side of the wrist together with Finkelstein's test for de Quervain's disease, lateral epicondyle pain and Maudsley's test for tennis elbow, and the combination of Hoffman-Tinel sign and static 2-point discrimination (2-PD) for finger sensibility for nerve entrapment syndromes, adding Phalen's test specific for carpal tunnel syndrome [24-28]. 


\subsection{Purdue Pegboard Test}

The participants also underwent the Purdue Pegboard (PPB) Test, which is a neuropsychological test that involves different abilities: gross movements of arms, hands, and fingers, as well as fine motor extremity (also known as "fingerprint" dexterity), and bimanual dexterity [29,30]. It was originally intended as an industrial test for assessing the dexterity of assembly line workers [31]. Nowadays, the PPB Test is used, for example, to follow-up on and assess disabilities and limitations. The pegboard consists of a board with two parallel rows of 25 holes each into which cylindrical metal pegs are placed by the examinee. The test involves a total of four trials [32]. The subsets for preferred, non-preferred, and both hands require the patient to place the pins in the holes as quickly as possible, with the score being the number of pins placed in $30 \mathrm{~s}$.

There were only two different examiners (one for physical examination and one for the PPB Test) to optimise inter-rater reliability. The examiners were blinded to the questionnaire responses.

\subsection{Statistical Analysis}

All statistical analyses were performed using the SAS software version 9.4 (SAS Institute Inc./Cary, NC, USA). The primary analysis consisted of two parallel tests, which proved the hypothesis of equivalence of a respective test group and the reference group. This confirmatory analysis referred to the disability/symptom DASH score (without the two optional modules) and used the two-one-sided $t$-test (TOST) procedure [33]. Both the grinding and the packaging groups were compared to the control group. The significance levels of the equivalence tests were adjusted according to Bonferroni, resulting in two-sided $t$-test levels of 0.025 [34]. The equivalence of two groups was considered proven if the observed difference between them was significantly lower than the equivalence margin, which was set to 15 points [35]. The $95 \%$ simultaneous confidence intervals for differences from the control (Dunnett's method) were used to compare DASH scores [36].

For descriptive statistics with approximately normally distributed continuous data, the mean value and standard deviation (SD, shown in parentheses) were calculated. For clearly non-normally distributed data, especially skewed continuous data, the median and interquartile ranges (IQR, shown in parentheses with "_" between the two values) were calculated [37]. For categorical variables, absolute and relative frequencies were calculated. When reporting percentages for categorical data, the numerators and denominators of the calculations are always given in parenthesis.

Where statistical tests have been used for comparisons between groups, the two-sided p-values must be considered as measures of the effect size rather than as confirmatory values.

The sample size was calculated using nQuery Advisor 7.0 (Statistical Solutions Ltd., Cork, Ireland). The one-sided significance level used for individual $t$-tests in the TOST was set to 0.013. Assuming an expected group mean difference of 0 and a pooled standard deviation of 14.68 , the study has a power of $80 \%$ to detect equivalence when the sample size is 26 per group [38].

\section{Results}

Based on a basic population of about 3500 workers and employees, the total population after application of the inclusion criteria (age between 18 and 65 years, employment in the respective workplace for more than 5 years and not currently on sick leave) consisted of 63 subjects in group I, 208 in group II, and 2501 in group III (Figure 3). A random selection was made from this population for inclusion in the study. After completion of the questionnaires and taking the exclusion criteria into account, a total of 70 subjects (grinding $n=20$, packaging $n=24$, and control $n=26$ ) were included in the study. Six subjects were excluded, five for medical criteria and one because of absence from work due to upper extremity pain for more than two weeks within the last three months. 


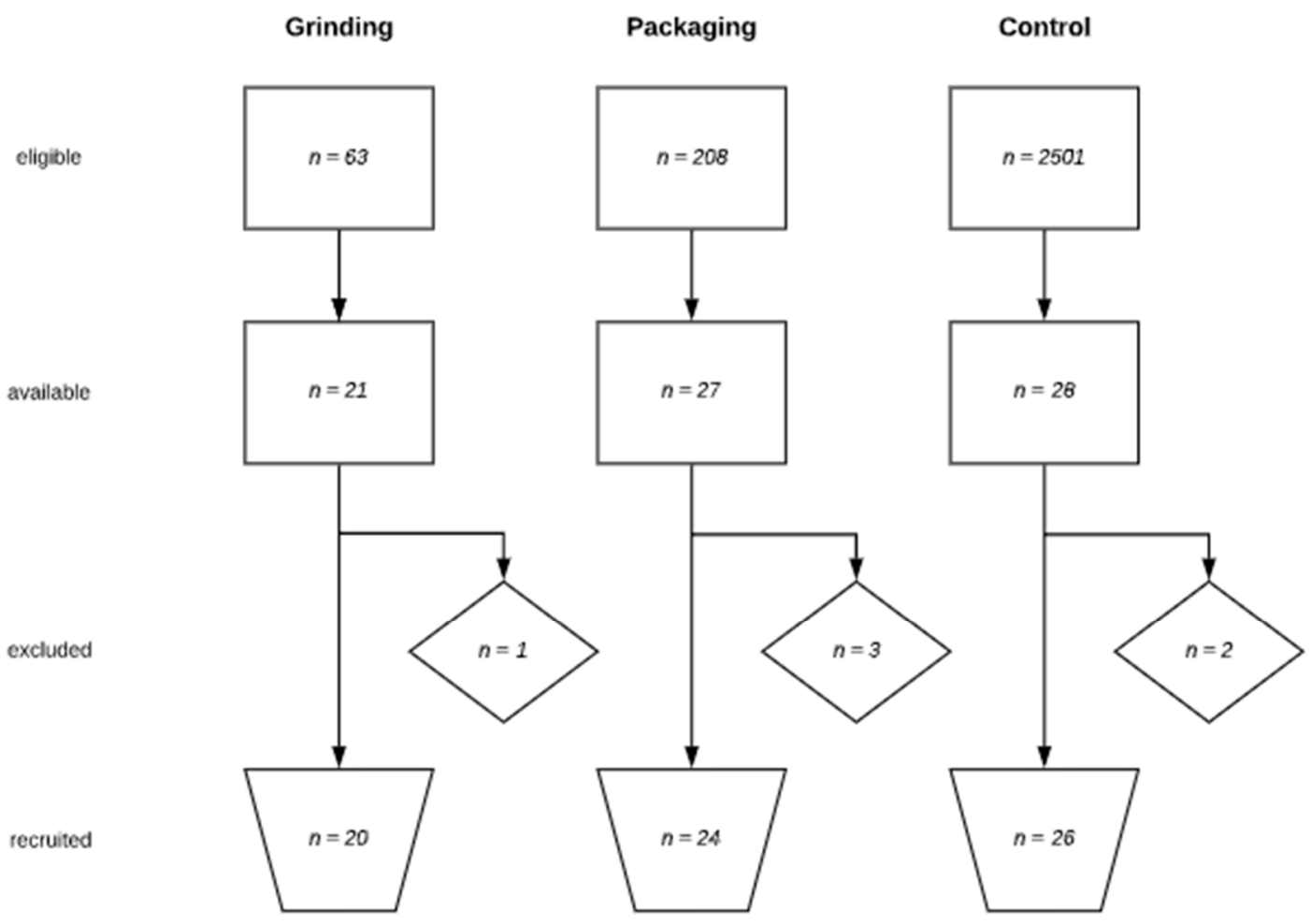

Figure 3. Study population flowchart.

\subsection{Demographic Data}

The majority of the study population was male (67\% (47/70)) and right-handed (83\% (55/70)). Very few had a secondary occupation (9\% (6/70)) and 61\% (43/70) reported having sporting or physical hobbies. The three groups had comparable demographic data with regard to age (42.1 (12.2) years), body mass index (BMI) $\left(26.2(5.0) \mathrm{kg} / \mathrm{m}^{2}\right)$, full volume of employment $(91 \%(64 / 70))$ and years of service at the company (16.1 (9 to 28) years) (Tables 2 and 3).

Table 2. Demographic data: categorical parameters.

\begin{tabular}{|c|c|c|c|}
\hline & Grinding $(n=20)$ & Packaging $(n=24)$ & Control $(n=26)$ \\
\hline \multicolumn{4}{|l|}{ Sex } \\
\hline Female & $25 \%(5 / 20)$ & $38 \%(9 / 24)$ & $35 \%(9 / 26)$ \\
\hline Male & $75 \%(15 / 20)$ & $62 \%(15 / 24)$ & $65 \%(17 / 26)$ \\
\hline \multicolumn{4}{|l|}{ Handedness } \\
\hline Right & $70 \%(14 / 20)$ & $92 \%(22 / 24)$ & $85 \%(22 / 26)$ \\
\hline Left & $30 \%(6 / 20)$ & $8 \%(2 / 24)$ & $15 \%(4 / 26)$ \\
\hline Secondary occupation & $15 \%(3 / 20)$ & $4 \%(1 / 24)$ & $8 \%(2 / 26)$ \\
\hline Sporting and physical hobbies & $55 \%(11 / 20)$ & $54 \%(13 / 24)$ & $73 \%(19 / 26)$ \\
\hline Employment volume less than full time & $5 \%(1 / 20)$ & $13 \%(3 / 24)$ & $8 \%(2 / 26)$ \\
\hline
\end{tabular}

Table 3. Demographic data: continuous parameters.

\begin{tabular}{cccc}
\hline & Grinding $(\boldsymbol{n}=\mathbf{2 0})$ & Packaging $(\boldsymbol{n}=\mathbf{2 4 )}$ & Control $(\boldsymbol{n}=\mathbf{2 6})$ \\
\hline & Mean (SD)/Median (IQR) & Mean (SD)/Median (IQR) & Mean (SD)/Median (IQR) \\
\hline Age (years) & $41.7(13.1)$ & $42.6(11.9)$ & $42.0(12.3)$ \\
BMI $\left(\mathrm{kg} / \mathrm{m}^{2}\right)$ & $27.1(4.6)$ & $25.3(5.6)$ & $26.4(4.6)$ \\
Years of service & $13.5(7-31)$ & $13.8(9-28)$ & $17.3(10-27)$ \\
\hline
\end{tabular}




\subsection{DASH Outcome Measure}

The DASH scores for each of the three groups, including the optional sports/music and work modules, are shown in Table 4. Our mean scores are in good agreement with the normative DASH scores [38]. Remarkably, the values from the grinding and packaging groups were about double those the control group when we analysed the sports/music and work modules. Note that lower DASH scores are associated with a better situation.

Table 4. Disabilities of the Arm, Shoulder and Hand (DASH) scores.

\begin{tabular}{ccccc}
\hline & $\begin{array}{c}\text { Grinding } \\
(\boldsymbol{n}=\mathbf{2 4})\end{array}$ & $\begin{array}{c}\text { Packaging } \\
(\boldsymbol{n}=\mathbf{2 4})\end{array}$ & $\begin{array}{c}\text { Control } \\
(\boldsymbol{n}=\mathbf{2 6})\end{array}$ & Reference Values \\
\hline Mean (SD) & Mean (SD) & Mean (SD) & Mean (SD) \\
\hline $\begin{array}{c}\text { DASH score } \\
\text { DASH }\end{array}$ & $8.5(7.6)$ & $12.0(10.6)$ & $7.9(8.1)$ & $10.1(14.7)$ \\
sports/music score & $12.5(13.9)$ & $12.0(18.2)$ & $4.5(8.0)$ & $9.8(22.7)$ \\
DASH work score & $14.9(15.3)$ & $13.0(18.1)$ & $6.8(10.5)$ & $8.8(18.4)$ \\
\hline
\end{tabular}

\subsection{Clinical Relevance Testing}

The distribution of the values of the DASH score in the three groups is shown in Figure 4. Both separate TOST-based tests for equivalence (grinding vs. control and packaging vs. control) demonstrated equivalence with the 15-point margin (all $p$-values $<0.0001$ ). The mean score differences with corresponding 95\% confidence limits are shown in Table 5.

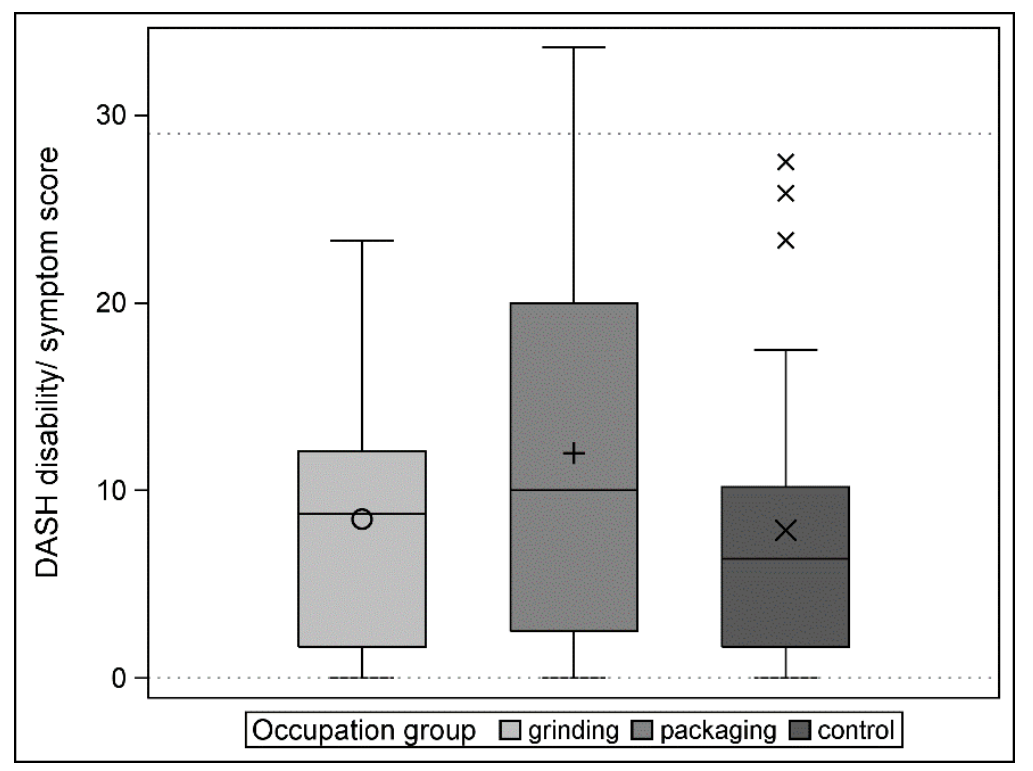

Figure 4. Distribution of the DASH score in the three groups.

Table 5. Results of the TOST-based tests.

\begin{tabular}{cccc}
\hline Test & Mean Difference with 95\% CI & Equivalence Range & Assessment \\
\hline Grinding vs. control & $0.6(-4.3,5.5)$ & $(-15 ; 15)$ & Equivalent \\
Packaging vs. control & $4.1(-1.2,9.5)$ & $(-15 ; 15)$ & Equivalent \\
\hline
\end{tabular}

The primary analysis proved that both grinding and packaging were equivalent to the control group. As the equivalence margins were set in respect to the minimal clinically important difference (MCID), these results support the evidence that the differences between the groups were not clinically 
relevant. Aside from the clinical relevance, the observed differences were proven to be statistically significant with $95 \%$ confidence intervals (Table 6).

Table 6. Results of Dunnett's test.

\begin{tabular}{ccc}
\hline Test & Mean Difference with Simultaneous 95\% CI (Dunnett) & Assessment \\
\hline Grinding vs. control & $0.6(-5.6,6.8)$ & CI contains 0 \\
Packaging vs. control & $4.1(-1.7,9.9)$ & CI contains 0 \\
\hline
\end{tabular}

As both $95 \%$ simultaneous confidence intervals for difference do contain zero, the significance of the observed differences at the $5 \%$ level can also be denied.

Exploratively, we divided the DASH score in the individual groups according to gender. A clearly different structure in the distribution between men (homogeneous) and women (variable) was observed (Figure 5).

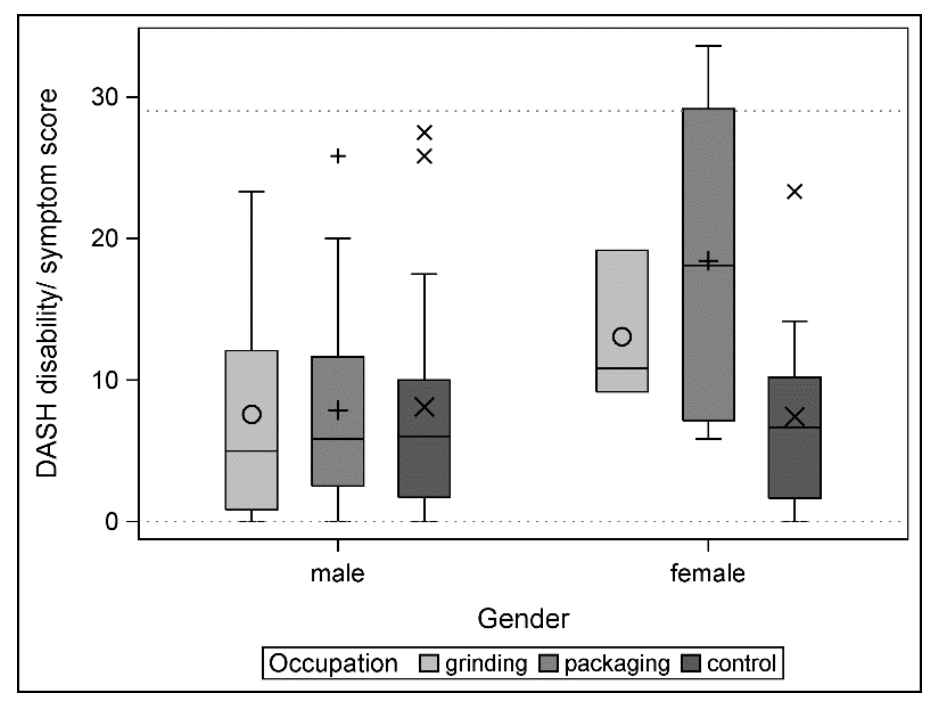

Figure 5. Distribution of the DASH disability/symptom score by gender.

\subsection{Clinical Data}

Upper extremity pain (i.e., symptoms) was reported in the questionnaire by $40 \%(8 / 20)$ of grinders, $58 \%(14 / 24)$ packers, and $42 \%$ (11/26) of the control group.

Pathognomonic clinical signs for upper extremity WMSDs (i.e., diagnoses) at the elbow, forearm and/or wrist (trigger finger, Finkelstein's test, Maudsley's test, Hoffman-Tinel sign, and Phalen's test) were found in $56 \%$ (39/70) of the people examined. The frequency of one or more diagnoses was $60 \%$ (12/20) for grinders, $58 \%$ (14/24) for packers, and 50\% (13/26) in the control group (Table 7). Bilateral manifestation was present in 34\% (24/70) and 14\% (10/70) of the subjects had two or more different pathologies in the ipsilateral limb. In the case of a positive Hoffmann-Tinel sign, it was mostly present at the medial elbow as a sign of ulnar tunnel syndrome. 
Table 7. Clinical data: prevalence of pathognomonic clinical signs.

\begin{tabular}{cccc}
\hline & Grinding $(\boldsymbol{n = 2 0 )}$ & Packaging $(\boldsymbol{n}=\mathbf{2 4 )}$ & Control $(\boldsymbol{n}=\mathbf{2 6})$ \\
\hline Pain at elbow/forearm and/or wrist & $40 \%(8 / 20)$ & $58 \%(14 / 24)$ & $42 \%(11 / 26)$ \\
Trigger finger & $10 \%(2 / 10)$ & $17 \%(4 / 24)$ & $4 \%(1 / 26)$ \\
Finkelstein's test & $15 \%(3 / 20)$ & $13 \%(3 / 24)$ & $4 \%(1 / 26)$ \\
Maudsley's test (middle finger test) & $15 \%(3 / 20)$ & $17 \%(4 / 24)$ & $12 \%(3 / 26)$ \\
Hoffman-Tinel sign & $40 \%(8 / 20)$ & $21 \%(5 / 24)$ & $31 \%(8 / 26)$ \\
Phalen's test & $20 \%(4 / 20)$ & $8 \%(2 / 24)$ & $4 \%(1 / 26)$ \\
\hline
\end{tabular}

The sensitivity of the upper extremity pain (symptoms) to the gold standard of pathognomonic clinical signs (diagnoses) was 54\% (21/39) whereas the specificity was 61\% (19/31) (Table 8).

Table 8. Cross table with clinical signs (diagnoses) and upper extremity pain (symptoms).

\begin{tabular}{cccc}
\hline \multirow{2}{*}{ Clinical signs } & & \multicolumn{2}{c}{ Upper Extremity Pain } \\
\cline { 3 - 4 } & & No & Yes \\
\cline { 2 - 4 } & No & $27 \%(19 / 70)$ & $26 \%(18 / 70)$ \\
\hline \multirow{2}{*}{ Yes } & $17 \%(12 / 70)$ & $30 \%(21 / 70)$ \\
\hline
\end{tabular}

In our sample there were three packers with a DASH score $>29$, while in the control group there was no such case (OR $8.63(0.40 ; 186.88))$. In the grinder group, 14 subjects were diagnosed with upper extremity WMSD, in the control group these were only 12 (OR $2.59(0.76 ; 8.78)$ ). Further odds ratios are shown in Table 9.

Table 9. Odds ratios for important outcomes.

\begin{tabular}{ccc}
\hline Endpoint & Effect & Odds Ratio Estimate (Lower; Upper 95\% Confidence Limit) \\
\hline DASH $>29$ & Grinding vs. control & $1.29(0.02 ; 74.11)$ \\
DASH $>29$ & Packaging vs. control & $8.63(0.40 ; 186.88)$ \\
Arm pain & Grinding vs. control & $0.92(0.28 ; 2.99)$ \\
Arm pain & Packaging vs. control & $1.86(0.61 ; 5.72)$ \\
Any diagnosis & Grinding vs. control & $2.59(0.76 ; 8.78)$ \\
Any diagnosis & Packaging vs. control & $1.36(0.45 ; 4.14)$ \\
\hline
\end{tabular}

Continuous clinical parameters are shown in Table 10. A visual analogue scale (VAS) was used for pain evaluation at rest and under stress. Wrist mobility (range of motion in three planes) and grip strength were also collected. No relevant differences could be found between the groups. We did not expect any relevant differences between the right and left hand, therefore we used mean values for further analysis. When comparing grip strength with reference values from a healthy population, subdivided according to sex and age group, below-average values were found in all three groups [39]. The values for men were twice as high as the values for women (Figure 6). 
Table 10. Clinical data: continuous parameters.

\begin{tabular}{ccccc}
\hline & Grinding $(\boldsymbol{n}=\mathbf{2 0})$ & Packaging $(\boldsymbol{n}=\mathbf{2 4})$ & Control $(\boldsymbol{n}=\mathbf{2 6})$ & Reference Values \\
\hline & Mean (SD) & Mean (SD) & Mean (SD) & Mean (SD) \\
\hline VAS at rest (points) & $1.4(0.9)$ & $2.0(2.0)$ & $1.5(1.0)$ & - \\
VAS at stress (points) & $2.5(2.5)$ & $3.0(2.3)$ & $2.2(1.9)$ & - \\
ROM E/F (degrees) & $125.6(15.9)$ & $125.5(14.5)$ & $123.8(11.3)$ & - \\
ROM S/P (degrees) & $176.0(8.2)$ & $177.8(7.3)$ & $178.8(5.9)$ & - \\
ROM U/R (degrees) & $50.5(2.2)$ & $51.4(3.8)$ & $51.0(3.7)$ & - \\
$\quad$ Grip strength & $50.7(11.1)$ & $46.8(17.5)$ & $46.0(11.8)$ & $54(7)$ \\
$\quad$ (kg)—male & $26.2(5.7)$ & $27.5(5.3)$ & $27.8(4.6)$ & $32(6)$ \\
Grip strength & & & \\
(kg)_female & & &
\end{tabular}

VAS = pain on visual analogue scale, $\mathrm{ROM}=$ range of motion, $\mathrm{E} / \mathrm{F}=$ extension/flexion, $\mathrm{S} / \mathrm{P}=$ supination/pronation, $\mathrm{U} / \mathrm{R}=$ ulnar/radial abduction.

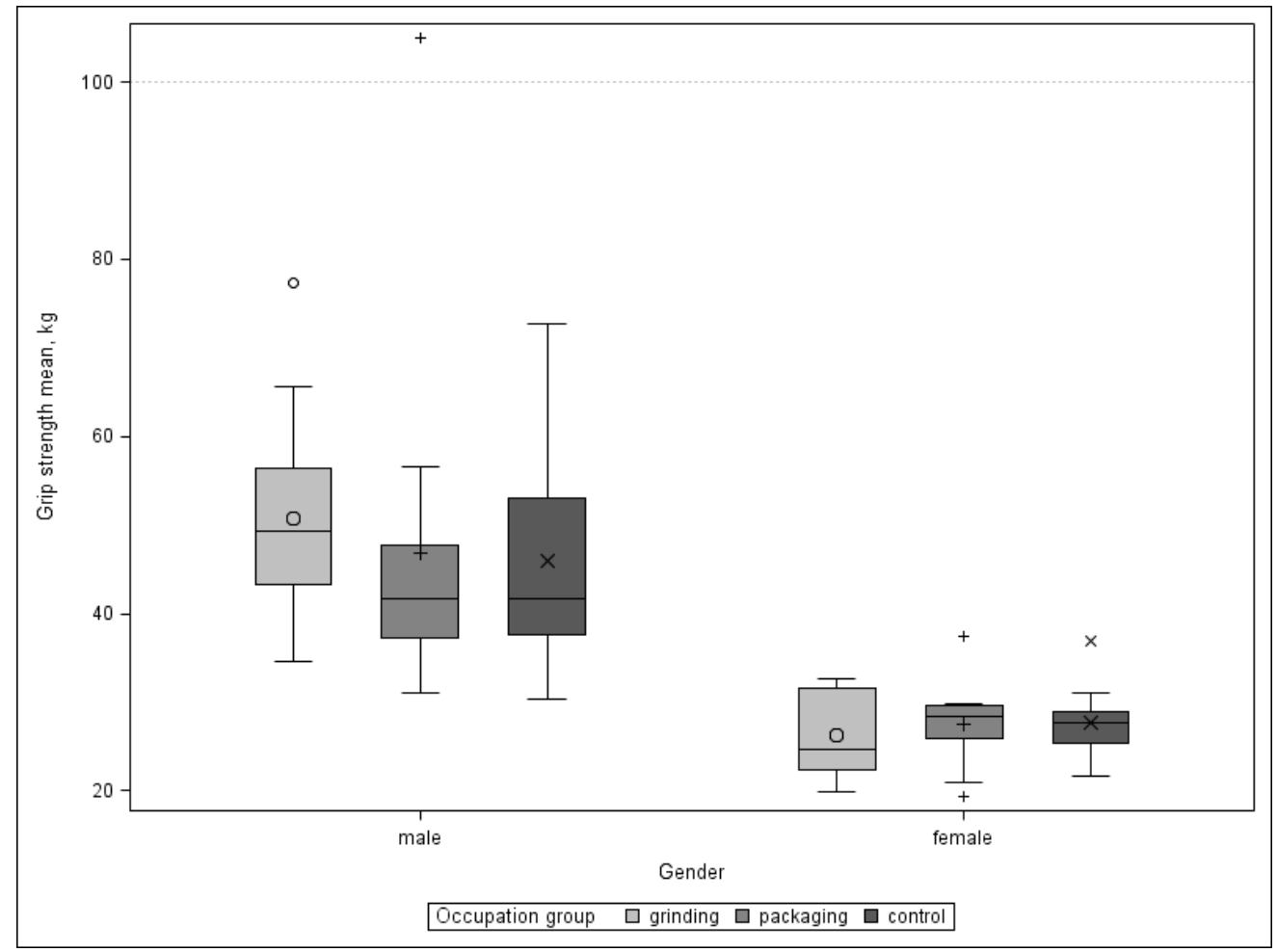

Figure 6. Grip strength by gender.

\subsection{Purdue Pegboard Test}

The results of the Purdue Pegboard Test (PPB) are shown in Table 11. Test 4 was chosen to represent the PPB as this summarises Tests 1 to 3 well by adding them up. As Tests 1 to 3 may be expected to correlate, Test 4 should show the potential differences between the groups more clearly. The intergroup comparison of the Purdue Pegboard Test showed no relevant differences. When comparing the values with the reference values, the values were mostly below average, e.g., 44.2 points for men and 41.2 points for women for the PPB Test 4 [40]. 
Table 11. Results of the Purdue Pegboard Test (in points).

\begin{tabular}{ccccc}
\hline & Grinding $(\boldsymbol{n}=\mathbf{2 0})$ & Packaging $(\boldsymbol{n}=\mathbf{2 4 )}$ & Control $(\boldsymbol{n}=\mathbf{2 6 )}$ & Reference Values \\
\hline & Mean (SD) & Mean (SD) & Mean (SD) & Mean (SD) * \\
\hline Preferred hand (Test 1) & $14.30(2.08)$ & $15.00(2.09)$ & $15.42(2.18)$ & $15.47(1.8)$ \\
Non-preferred hand (Test 2) & $13.60(2.04)$ & $14.25(1.89)$ & $14.62(2.37)$ & $14.94(1.86)$ \\
Both hands (Test 3) & $11.65(2.18)$ & $11.54(1.25)$ & $12.35(1.62)$ & $12.8(1.98)$ \\
Right + left + both hands & $39.55(5.00)$ & $40.79(3.80)$ & $42.38(5.32)$ & $43.21(-)$ \\
(Test 4) & $29.95(7.42)$ & $30.17(5.14)$ & $33.54(6.41)$ & $38.19(6.25)$ \\
Assemblies (Test 5) & &
\end{tabular}

* Calculated for the mean age category (40-49 years) and for the study population gender ratio (23/70 female) according to [40].

\section{Discussion}

Upper extremity WMSDs represent a range of disorders of the muscle, tendon, or nerve that also can occur in non-workplace settings with a similar or identical pathophysiology [16,41]. Musculoskeletal disorders are the most expensive disease category with regard to work absenteeism and disablement. We chose to survey a population of actively employed surgical device mechanics and compared them with a group of employees believed not to be exposed to repetitive hand and arm movements to such a large extent.

We conducted this prospective study at the headquarters and main production site of Aesculap AG, which is a leading manufacturer and global player in the surgical instrument industry, located in a medical technology cluster region [42,43]. Among other things, the company is valued for its comprehensive preventive medical treatment programmes that are easy for all its employees to access. One of the basic requirements for our study was for many of the employees to have been with the company for a long time and to have had a constant workplace over a long period of time.

\subsection{DASH and Other Measurement Values}

The DASH outcome measure has proven to be a reliable and valid instrument to measure physical function and symptoms in upper extremity musculoskeletal complaints, including WMSDs [44,45]. It is the best instrument for evaluating patients with upper limb joint disorders [46].

As in previous studies, it was observed that a non-clinical "normal" population does not have a zero value [47]. Both groups of manual workers tested in the current study proved their statistical equivalence with the control group. Since our equivalence margins correspond to the minimal clinically important difference (MCID) for the DASH score, we were able to state that neither grinders nor packers were clinically different from the control group. The mean DASH score in our investigation was 8.5 (SD 7.6) points for the grinder group, 12.0 (SD 10.6) points for the packer group, and 7.9 (SD 8.1) points for the control group. Although the control group had the best (=lowest DASH) score, the differences were not statistically significant. The reference value of 10.1 (SD 14.7) points was only exceeded by the packers; the other two groups were better than this threshold.

Surprisingly, it is not the grinders with their loading and repetitive activity tasks that have the highest (=worst) DASH score, but the packers whose work tasks are defined as repetitive with less loading and more variability in the movement sequences. This finding contrasts with a study which has shown significant differences in DASH scores between manually demanding and manually low-demanding jobs in favour of the latter [48]. One reason for this could be that working hours and job designs have changed significantly in the medical device industry in recent decades so there may be no relevant differences to other occupational groups with a lower workload. A lot of grinders repeatedly carry out pre-processing and post-processing activities, which lead the grinder away from the whetstone during a shift at today's modern workplaces. This is not the case with packers who mainly carry out the same work throughout a shift. A further explanation could be that the grinders are usually very experienced specialists who would be hard to replace in the event of health problems. This means that there is a particularly high level of motivation on the part of employers for health 
protection measures in this group. According to common doctrine, static work processes favour the development of upper extremity WRMDs, which should represent a risk for grinders [49]. In reality, however, there is no difference from the somewhat more variable and multidimensional movement sequences of the packers. It may even be possible that microvibrations in grinders could have a prophylactic effect preventing the development of WRMDs in the upper extremity [50].

The average values of the three investigated groups correspond to those of a population not employed in manual work. A literature review showed that our scores are generally lower than in most studies that have analysed normative values in the general population outside clinical settings [37,48,51-53]. We gained the impression that some test subjects had previously reported clinical complaints well below a DASH score of 29, which was defined by Williams as a kind of threshold [54]. In our sample, the risk of packers having clinically relevant complaints (DASH invalidity/symptom score $>29$ ) was higher (odds ratio $8.63(0.40 ; 186.88)$ ) than in the control group. However, this did not reach statistical significance.

Interestingly, the DASH showed a homogeneous distribution between the three groups in men, while women had a very inhomogeneous distribution. The influence of age (increasing DASH scores with increasing age) and gender (higher DASH scores in women) as well as further co-variates in this context will be topic of our future studies [48,52].

Active range of motion of the wrist and pain on the visual analogue scale (VAS) showed no abnormalities or relevant differences between the groups. The measured values for grip strength were partly below the published reference values, taking into account handedness, age, and sex [38,48]. In the Purdue Pegboard Tests our subjects mostly performed below than the reference values given $[40,55]$. This result is astonishing, because we would have expected a different result, especially for packers' repetitive and fine motor activities as well as for those of numerous workplaces in the inspection department.

\subsection{Prevalence of Symptoms and Diagnoses}

The design of our cross-sectional study with a control group, physical examination of the subjects, and the use of a questionnaire can be found in several studies related to different industries. Our literature research showed a prevalence of upper extremity pain (i.e., symptoms) of between $21 \%$ and $71 \%$ in the study group and between $6 \%$ and $50 \%$ in the control group [56-68]. This is in line with our investigation where symptoms were reported in the first questionnaire by $8 / 20(40 \%)$ grinders, $14 / 24(58 \%)$ packers, and $11 / 26(42 \%)$ people in the control group.

In most studies, only the symptoms of musculoskeletal disorders of the upper extremity were described, instead of additionally identifying pathognomonic clinical signs (i.e., diagnoses). In the latter the prevalence has ranged from $21 \%$ to $56 \%$ compared to $5 \%$ to $22 \%$ in the control group $[57,58,60-62,64]$. Upper limb musculoskeletal disorders were diagnosed in 14/20 (70\%) grinders, 13/24 (54\%) packers, and $11 / 26(42 \%)$ of the test persons in the control group for our investigation, with bilateral manifestation in approximately one third of cases. Thus, the frequency of reported symptoms is lower than the frequency of detected musculoskeletal disorders in our study, in contrast to previous studies which showed a high prevalence of complaints but a relatively low number of definite diagnoses $[69,70]$. One explanation could be the rather low sensitivity of the questionnaires to upper extremity complaints $(42 \%-65 \%)$, as already found by Ohlsson et al., which underlines the need for a combination of questionnaire and clinical investigation in such cross-sectional studies [71]. Another aspect could be the focus on diseases of the elbow, forearm, wrist, and hand in our investigation, which did not consider more proximal pathologies of the upper extremity, such as shoulder disorders. The latter are sometimes unspecific and there are hardly any pathognomonic clinical tests to make a reliable diagnosis. This could, in turn, lead to a gap between symptoms and diagnoses of diseases.

It has been shown that musculoskeletal disorders in different body regions are associated with different branches of industry. Lateral epicondylitis, wrist tendinitis and carpal tunnel syndrome are considered the most common diseases $[57,60-62,64,70]$. In our investigation, $30 \%$ of all test persons 
and $54 \%$ of the subjects with upper extremity complaints had signs of medial epicondylitis (golfer's elbow) and nerve entrapment at the medial elbow (cubital tunnel syndrome), followed by lateral epicondylitis (tennis elbow) in $14 \%$ and $27 \%$, respectively. Our literature research revealed a prevalence of medial epicondylitis (golfer's elbow) of $3 \%$ to $20 \%$ in occupational settings associated with forceful activities but without clear reference to repetitive work [64,72-75]. Medial epicondylitis occurs in only $10 \%-20 \%$ of all epicondylitis as a result of common flexor tendon microtrauma and degeneration, affects men and women equally, and is often associated with cubital tunnel syndrome [76]. We were able to confirm this above-average prevalence and the frequent co-occurrence of the two pathologies in our study. The risk for grinders of developing upper extremity WMSD was higher than in the control group (odds ratio $2.59(0.76 ; 8.78)$ ). However, there was no statistically significant increased occurrence of these pathologies in any of the groups.

\subsection{Interpretation of the Results}

We hypothesised that there would be no clinically relevant differences in the prevalence of upper extremity WMSDs between surgical device mechanics with specific repetitive work tasks, with and without forceful exertions, compared to other employees in the same industry. We were able to confirm this with surgical device mechanics not seeming to be at higher risk of upper limb WMSDs compared to the control group. Although grinders and packers had higher DASH values than the control group, this difference was of no clinical relevance and statistically not significant. However, there are partly contradictory statements in this regard from other sectors of industry [12-15,76]. The reasons for our findings are probably that the exposed groups did not vary much in terms of their physical workload and repetitive work tasks. However, since WMSDs represent a complex condition that can be influenced by individual, environmental, psychosocial, and organizational factors, this simplified interpretation is only one possible aspect in a multi-level approach with numerous interactions and thus might explain some contradictory results $[77,78]$. Variations in the duration of exposure, work interruptions through less monotonous and stressful pre-processing and post-processing activities, psychosocial factors, the level of training, and income disparities may have such an influence that the primary work tasks lose relevance with regard to upper extremity WMSDs $[65,66]$.

The diagnostic patterns observed in this investigation were, in general, consistent with medial epicondylitis and cubital tunnel syndrome in the elbow. Lateral epicondylitis, tenosynovitis in the wrist, and carpal tunnel syndrome were underrepresented. This can also be explained by the working positions at various workplaces, some of which were noticeable during our site inspections, with partially unpadded support of the elbows and proximal forearms on edges and surfaces (Figure 7).

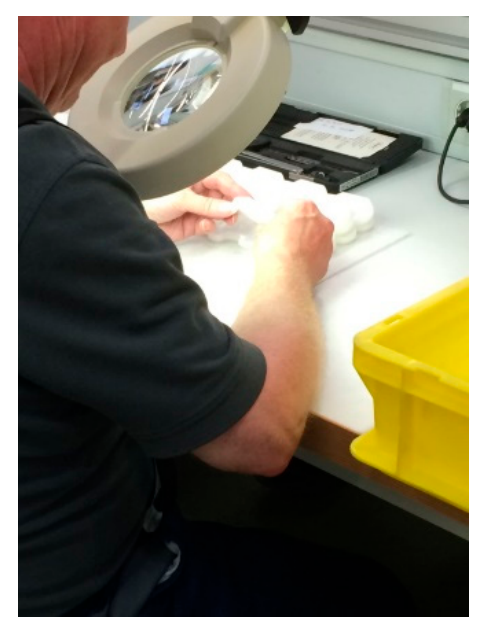

Figure 7. Unpadded position of the elbow and forearm creating risk of medial epicondylitis and ulnar nerve compression. 
In addition to regular occupational health check-ups, the study company offers optional preventive medical check-ups for individual complaints. Furthermore, there are check-up programs for each employee on a voluntary basis to identify risk factors, preliminary stages of illness or diseases, and to be able to prevent or treat them in a targeted manner. In the latter case, a full-body profile is created including patient history, blood values, Electrocardiogram (ECG), lung function testing, visual and hearing tests, as well as a full body examination, including different organ systems. If particularities are identified during these examinations, further targeted measures may be taken. In the case of upper extremity WMSDs, hand therapeutic measures, ergonomic optimization of the workplace, and examinations by specialists (e.g., upper extremity surgeon) are usually initiated. Based on our study results, the response to the strikingly high rates of medial elbow pathologies should be an ergonomic sitting position and simple padding of the table edges. Longer periods of repetitive work, especially for packers, should be interrupted by other types of work, including job rotation as a preventive measure.

\subsection{Limitations of Our Investigation}

There is a possible evaluation bias as it was not possible to blind clinical evaluators due to the participants' clothing (blue collar vs. white collar workers). Thus, we believe that the bias is small, if present. A selection bias is also likely as persons with upper extremity complaints could be more motivated to volunteer. However, since this effect applies equally to the study groups and the control group, it would be cancelled out and at the same time increase the total number of complaints. This last effect may partly be compensated by the healthy worker effect, which often results in the working population being statistically shown to be healthier than is actually the case. People with pain and functional disorders might leave their work, and cross-sectional studies thus may underestimate the risk. The only validated test available for our series is the self-reported DASH outcome measure. However, the ability of subjects with musculoskeletal disorders cannot be assessed on the basis of questionnaires alone. As in every questionnaire, the translation of scores from the questionnaire to functional capacity for work can be questioned. Furthermore, our cross-sectional data has inherent limitations, including the inability to clearly distinguish clinically between the chronic, recurrent, and acute symptoms we observed. In addition to biomechanical constraints, psychosocial factors with difficult-to-define effects have been shown to play a role in the genesis of WMSDs [79-81]. We have not included this aspect as a contributing cause in our analysis to prioritise other questions and due of the high complexity of its evaluation. In fact, grinders are skilled workers with good pay, while packers are mostly lateral entrants and semi-skilled workers with lower incomes. As we performed a cross-sectional study, the causality of our reported pathologies could not be assessed. We could not adjust for workers' baseline risk of WMSDs resulting from prior occupational exposures or other non-occupational exposures. In this case, a longitudinal study, including the time dimension, would be advantageous in order to better decide what changes should be made to working conditions. The overall very high level of preventive measures and occupational health care for the entire workforce could be a reason why no significant differences could be found between the groups. Despite the size of the company, the subdivision into specific working groups with certain tasks leads to a relatively small number of cases, which is especially true for the grinders. However, a smaller subdivision would have reduced the selectivity. The sample size was calculated based on anticipated effect in order to enable the proof of the study hypothesis of equivalence between occupational groups (see statistical analysis). The targeted sample size could not be achieved in all groups due to lack of consent in smaller subpopulations. Nevertheless, the actual sample sizes were sufficient to prove the study hypotheses.

Planning the current study, we assumed a normal distribution for the DASH score. The statistical analyses followed the a priori plan in order to maintain the significance level. The distribution analysis of the study data revealed an obvious ceiling effect, with 12 of 70 participants having the best score of 0 pts. Normal distribution-based statistical methods may lose sensitivity in terms of detecting differences between groups, with respect to the power to detect effects in such a situation. The ceiling is not unusual in studies using scores for outcome evaluation, particularly studies in orthopaedics, 
and should be taken into account when planning statistical analysis for future studies using DASH scores [82].

\subsection{Strengths of Our Investigation}

The strengths of this study include the comparatively homogeneous study groups of healthy and physically active subjects as well as the above-average length of service of the employees with low job turnover, which should keep confounding to a minimum. In a lot of studies of WMSDs, the workplace data come from case series compiled from records of reportable injuries and illnesses kept by the employer's liability insurance companies and the in-plant medical departments. Since these sources identify late-stage disorders that prompt workers to seek medical attention, the data probably identify an incomplete subset of cases and underestimate the true rates of disease. With regard to the study design of our investigation, the combination of self-administered questionnaire and specific face-to-face physical assessment has proven effective in obtaining a consistent study result. Thereby the criteria for specific and reliable assessment of the functional capacity of the forearm and hand according to Wind et al. were met [44]. Furthermore, the physical examinations were performed by the same hand surgeon and the testing by the same hand therapist. Such a set-up was very rare in previous studies and may have influenced the frequency of detected diagnoses of WMSDs. Our aim was to keep well-defined disorders separate from more diffuse conditions. When examining the test subjects, we adhered to the classification system as described by Van Eerd et al., which proposes specific diagnoses for muscle, tendon, and nerve disorders rather than a description of the signs and symptoms found [45].

\section{Conclusions}

Our findings do not indicate that repetitive work with and without forceful exertions is associated with a higher risk of upper extremity WMSD in surgical device mechanics compared to a control group, but small effects cannot be ruled out. Although a high standard of occupational health and safety measures can be assumed within the study company, the pathologies frequently found in the medial elbow may be due to specific working practices. Based on the results of this study, targeted occupational health measures can be designed and implemented with the aim of both preventing and treating upper extremity musculoskeletal disorders [83]. Once these measures have been implemented, we recommend re-evaluating the groups over time in a longitudinal study. This is the first study to analyse this specific industry and compare different workplaces and their work tasks. Comparable loading and repetitive activities can also be found in other industries.

Author Contributions: Conceptualization, O.L., J.M. and T.L.; methodology, O.L. and J.M.; software, V.B.; validation, T.L. and O.L.; formal analysis, V.B.; investigation, O.L. and T.L.; resources, J.M.; data curation, J.M. and V.B.; writing-original draft preparation, O.L. and V.B.; writing-review and editing, all authors; visualization, T.L.; supervision, O.L.; project administration, J.M. All authors have read and agreed to the published version of the manuscript.

Funding: This research received no external funding.

Acknowledgments: The authors would like to thank all study participants and the staff involved in the conduct of the study, in particular Katharina Lange, Manager Medical Scientific Affairs, Aesculap AG; Mrs Stefanie Latuske, Mrs Mevlüde Orhan and Mrs Ulrike Hofer, Health Centre, Aesculap AG.

Conflicts of Interest: The authors declare no conflict of interest.

\section{References}

1. Bernard, B.P. Musculoskeletal Disorders and Workplace Factors: A Critical Review of Epidemiologic Evidence for Work-Related Musculoskeletal Disorders of the Neck, Upper Extremity, and Low Back, 1st ed.; National Institute for Occupational Safety and Health Publication: Cincinnati, OH, USA, 1997; pp. 234-236.

2. Baldwin, M.L.; Butler, R.J. Upper extremity disorders in the workplace: Costs and outcomes beyond the first return to work. J. Occup. Rehabil. 2006, 16, 303-323. [CrossRef] [PubMed] 
3. Latko, W.A.; Armstrong, T.J.; Franzblau, A.; Ulin, S.S.; Werner, R.A.; Albers, J.W. Cross-sectional study of the relationship between repetitive work and the prevalence of upper limb musculoskeletal disorders. Am. J. Ind. Med. 1999, 36, 248-259. [CrossRef]

4. Buckle, P.W.; Devereux, J.J. The nature of work-related neck and upper limb musculoskeletal disorders. Appl. Ergon. 2002, 33, 207-217. [CrossRef]

5. Werner, R.A.; Franzblau, A.; Gell, N.; Ulin, S.S.; Armstrong, T.J. Predictors of upper extremity discomfort: A longitudinal study of industrial and clerical workers. J. Occup. Rehabil. 2005, 15, 27-35. [CrossRef] [PubMed]

6. Dale, A.M.; Ryan, D.; Welch, L.; Olsen, M.A.; Buchholz, B.; Evanoff, B. Comparison of musculoskeletal disorder health claims between construction floor layers and a general working population. Occup. Environ. Med. 2015, 72, 15-20. [CrossRef]

7. Palmer, K.; Coggon, D.; Cooper, C.; Doherty, M. Work related upper limb disorders: Getting down to specifics. Ann. Rheum. Dis. 1998, 57, 445-446. [CrossRef]

8. Jensen, L.K.; Hansen, H.B. Working environment. Many work impediments among personnel in operating room. Sygeplejersken 1986, 86, 4-10.

9. Sorgatz, H. Repetitive strain injuries. Orthopaede 2002, 31, 1006-1014. [CrossRef]

10. Hagberg, M.; Silverstein, B.; Wells, R. Evidence of work relatedness for selected musculoskeletal disorders of the neck and limbs. In Work-Related Musculoskeletal Disorders (WMSDs): A Reference Book for Prevention, 1st ed.; Kuorinka, I., Forcier, L., Eds.; Taylor \& Francis: London, UK, 1995; Volume 1, pp. 17-138.

11. Milread, E.; Ercison, M.O. Effects of precision and force demands, grip diameter and arm support during manual work. Ergonomics 1994, 37, 255-264. [CrossRef]

12. Bonde, J.P.; Mikkelsen, S.; Andersen, J.H.; Fallentin, N.; Baelum, J.; Svendsen, S.W.; Thomsen, J.F.; Frost, P.; Kaergaard, A. Understanding work related musculoskeletal pain: Does repetitive work cause stress symptoms? Occup. Environ. Med. 2005, 62, 41-48. [CrossRef]

13. Kilbom, S.; Armstrong, T.; Buckle, P.; Fine, L.; Hagberg, M.; Haring-Sweeney, M. Musculoskeletal Disorders: Work-related Risk Factors and Prevention. Int. J. Occup. Environ. Health 1996, 22, 239-246.

14. Davis, T.R. Do repetitive tasks give rise to musculoskeletal disorders? Occup. Med. 1999, 49, $257-258$. [CrossRef] [PubMed]

15. Descatha, A.; Roquelaure, Y.; Chastang, J.F.; Evanoff, B.; Cyr, D.; Leclerc, A. Description of outcomes of upper-extremity musculoskeletal disorders in workers highly exposed to repetitive work. J. Hand Surg. 2009, 34, 890-895. [CrossRef] [PubMed]

16. Armstrong, T.J.; Buckle, P.; Fine, L.J. A conceptual model of work-related neck and upper limb disorders. Scand. J. Work Environ. Health 1993, 19, 73-84. [CrossRef] [PubMed]

17. Holness, D.L.; Beaton, D.; House, R.A. Prevalence of upper extremity symptoms and possible risk factors in workers handling paper currency. Occup. Med. 1998, 48, 231-236. [CrossRef] [PubMed]

18. Gerr, F.; Fethke, N.B.; Merlino, L.; Anton, D.; Rosecrance, J.; Jones, M.P. A prospective study of musculoskeletal outcomes among manufacturing workers: I. Effects of physical risk factors. Hum. Factors 2014, 56, 112-130. [CrossRef]

19. Offenbächer, M.; Ewert, T.; Sangha, O.; Stucki, G. Validation of a German version of the 'Disabilities of Arm, Shoulder and Hand' questionnaire (DASH-G). Z. Rheumatol. 2003, 62, 168-177. [CrossRef]

20. Germann, G.; Harth, A.; Wind, G.; Demir, E. Standardisation and validation of the German version 2.0 of the Disability of Arm, Shoulder, Hand (DASH) questionnaire. Unfallchirurg 2003, 106, 13-19. [CrossRef]

21. Hudak, P.L.; Amadio, P.C.; Bombardier, C. Development of an upper extremity outcome measure: The DASH (disabilities of the arm, shoulder and hand). Am. J. Ind. Med. 1996, 29, 602-608. [CrossRef]

22. Beaton, D.E.; Davis, A.M.; Hudak, P.; Macconell, S. The DASH (Disabilities of the Arm, Shoulder and Hand) Outcome Measure: What do we know about it now? Hand Ther. 2001, 24, 233-241. [CrossRef]

23. Waris, P.; Kuorinka, I.; Kurppa, K.; Luopajärvi, T.; Virolainen, M.; Pesonen, K.; Nummi, J.; Kukkonen, R. Epidemiologic screening of occupational neck and upper limb disorders. Methods and criteria. Scand. J. Work Environ. Health 1979, 5, 25-38. [CrossRef] [PubMed]

24. Ryf, C.; Weymann, A. The neutral zero method-A principle of measuring joint function. Injury 1995, 26, 1-11. [CrossRef]

25. Finkelstein, H. Stenosing tendovaginitis at the radial styloid process. J. Bone Joint Surg. 1930, 12, 509-540.

26. Sheon, R.E.; Moskowitz, R.W.; Goldberg, V.M. Soft Tissue Rheumatic Pain: Recognition, Management, Prevention, 2nd ed.; Lea \& Febiger: Philadelphia, PA, USA, 1988; pp. 122-198. 
27. Phalen, G.S. The carpal tunnel syndrome: Seventeen years' experience in diagnosis and treatment of 654 hands. J. Bone Joint Surg. 1966, 48, 211-228. [CrossRef]

28. Leclerc, A.; Landre, M.; Chastang, J.; Niedhammer, I.; Roquelaure, Y. Study Group on Repetitive Work. Upper-limb disorders in repetitive work. Scand. J. Work Environ. Health 2001, 27, 268-278. [CrossRef]

29. Strauss, E.; Sherman, E.M.S.; Spreen, O. A Compendium of Neuropsychological Tests: Administration, Norms, and Commentary, 3rd ed.; Oxford University Press: Oxford, UK, 2006; pp. 223-245.

30. Guralnik, J.M.; Fried, L.P.; Simonsick, E.M.; Kasper, J.D.; Lafferty, M.E. The Women's Health and Aging Study: Health and Social Characteristics of Older Women with Disability, 1st ed.; National Institute of Aging: Bethesda, MD, USA, 1995; pp. 234-239.

31. Radomski, V.M.; Trombly, C.A. Occupational Therapy for Physical Dysfunction, 1st ed.; Wolters Kluwer/Lippincott Williams \& Wilkins: Baltimore, MD, USA, 2008; ISBN 07817631269780781763127.

32. Golden, C.J.; Espe-Pfeifer, P.; Wachsler-Felder, J. Neuropsychological Interpretations of Objective Psychological Tests, 1st ed.; Springer: Heidelberg, Germany, 2006; pp. 174-179.

33. Schuirmann, D. A comparison of the Two One-Sided Tests Procedure and the Power Approach for assessing the equivalence of average bioavailability. J. Pharmacokinet. Biopharm. 1987, 15, 657-680. [CrossRef]

34. Dunn, O.J. Multiple comparisons among means. J. Am. Stat. A 1961, 56, 52-64. [CrossRef]

35. Beaton, D.E.; Katz, J.N.; Fossel, A.H.; Wright, J.G.; Tarasuk, V.; Bombardier, C. Measuring the whole or the parts? Validity, reliability, and responsiveness of the Disabilities of the Arm, Shoulder and Hand outcome measure in different regions of the upper extremity. J. Hand Ther. 2001, 14, 128-146. [CrossRef]

36. Dunnett, C.W. A Multiple Comparison Procedure for Comparing Several Treatments with a Control. J. Am. Stat. Assoc. 1955, 50, 1096-1121. [CrossRef]

37. Lang, T.A.; Secic, M. How to Report Statistics in Medicine, 2nd ed.; American College of Physicians: Philadelphia, PA, USA, 2006; pp. 441-443.

38. Hunsaker, F.G.; Cioffi, D.A.; Amadio, P.C.; Wright, J.G.; Caughlin, B. The American academy of orthopaedic surgeons outcomes instruments: Normative values from the general population. J. Bone Joint Surg. Am. 2002, 84, 208-215. [CrossRef]

39. Guenther, C.M.; Bürger, A.; Rickert, M.; Crispin, A.; Schulz, C.U. Grip strength in healthy caucasian adults: Reference values. J. Hand Surg. Am. 2008, 33, 558-565. [CrossRef] [PubMed]

40. Agnew, J.; Bolla-Wilson, K.; Kawas, C.H.; Bleeker, M.L. Purdue Pegboard age and sex norms for people 40 years old and older. Dev. Neuropsych. 1988, 4, 29-35. [CrossRef]

41. Staal, J.B.; de Bie, R.A.; Hendriks, E.J. Aetiology and management of work-related upper extremity disorders. Best Pract. Res. Clin. Rheumatol. 2007, 21, 123-133. [CrossRef] [PubMed]

42. BBraun Company: Numbers and Facts. Available online: https://www.bbraun.de/de/unternehmen/ organisation-zahlen-und-fakten.html (accessed on 5 June 2019).

43. Weltzentrum der Medizintechnik: Start. Available online: www.weltzentrum-der-medizintechnik.de (accessed on 13 June 2019).

44. Kitis, A.; Celik, E.; Aslan, U.B.; Zencir, M. DASH questionnaire for the analysis of musculoskeletal symptoms in industry workers: A validity and reliability study. Appl. Ergon. 2009, 40, 251-255. [CrossRef] [PubMed]

45. Wajngarten, D.; Campos, J.Á.D.B.; Garcia, P.P.N.S. The Disabilities of the Arm, Shoulder and Hand scale in the evaluation of disability-A literature review. Med. Lav. 2017, 108, 314-323. [PubMed]

46. Changulani, M.; Okonkwo, U.; Keswani, T.; Kalairajah, Y. Outcome evaluation measures for wrist and hand: Which one to choose? Int. Orthop. 2008, 32, 1-6. [CrossRef]

47. Klum, M.; Wolf, M.B.; Hahn, P.; Leclère, F.M.; Bruckner, T.; Unglaub, F. Normative data on wrist function. J. Hand Surg. Am. 2012, 37, 2050-2060. [CrossRef]

48. Jester, A.; Harth, A.; Rauch, J.; Germann, G. DASH data of non-clinical versus clinical groups of persons-A comparative study of T-norms for clinical use. Handchir. Mikrochir. Plast. Chir. 2010, 42, 55-64. [CrossRef]

49. Bovenzi, M.; Prodi, A.; Mauro, M. A longitudinal study of neck and upper limb musculoskeletal disorders and alternative measures of vibration exposure. Int. Arch. Occup. Environ. Health 2016, 89, 923-933. [CrossRef]

50. Macerollo, A.; Palmer, C.; Foltynie, T.; Korlipara, P.; Limousin, P.; Edwards, M.; Kilner, J.M. High-frequency peripheral vibration decreases completion time on a number of motor tasks. Eur. J. Neurosci. 2018, 48, 1789-1802. [CrossRef]

51. Jester, A.; Harth, A.; Germann, G. Measuring levels of upper-extremity disability in employed adults using the DASH Questionnaire. J. Hand Surg. Am. 2005, 30, 1074-1076. [CrossRef] [PubMed] 
52. Aasheim, T.; Finsen, V. The DASH and the QuickDASH instruments. Normative values in the general population in Norway. J. Hand Surg. Eur. Vol. 2014, 39, 140-144. [CrossRef] [PubMed]

53. Williams, N. The DASH Questionnaire. Occup. Med. 2014, 64, 67-68. [CrossRef] [PubMed]

54. Yeudall, L.T.; Fromm, D.; Reddon, R.; Stefanyk, W.O. Normative data stratified by age and sex for 12 neuropsychological tests. J. Clin. Psychol. 1986, 42, 918-946. [CrossRef]

55. Wind, H.; Gouttebarge, V.; Kuijer, P.F.M.; Frings-Dresen, M.H.W. Assessment of functional capacity of the musculoskeletal system in the context of work, daily living, and sport: A systematic review. J. Occup. Rehabil. 2005, 15, 253-272. [CrossRef]

56. Van Eerd, D.; Beaton, D.; Cole, D.; Lucas, J.; Hogg-Johnson, S.; Bombardier, C. Classification systems for upper-limb musculoskeletal disorders in workers: A review of the literature. J. Clin. Epidemiol. 2003, 56, 925-936. [CrossRef]

57. Lipscomb, H.J.; Epling, C.A.; Pompeii, L.A.; Dement, J.M. Musculoskeletal symptoms among poultry processing workers and a community comparison group: Black women in low-wage jobs in the rural South. Am. J. Ind. Med. 2007, 50, 327-338. [CrossRef]

58. Macdonald, F.; Waclawski, E. Upper limb disorders among coopers in the Scotch whisky industry. Occup. Med. 2006, 56, 232-236. [CrossRef]

59. Ohlsson, K.; Attewell, R.G.; Pålsson, B.; Karlsson, B.; Balogh, I.; Johnsson, B.; Kilbom, A.; Kuorinka, I.A.; Silverstein, B.A.; Sjogaard, G.; et al. Repetitive industrial work and neck and upper limb disorders in females. Am. J. Ind. Med. 1995, 27, 731-747. [CrossRef]

60. Ohlsson, K.; Hansson, G.A.; Balogh, I.; Strömberg, U.; Pålsson, B.; Nordander, C.; Rylander, L.; Skerfving, S. Disorders of the neck and upper limbs in women in the fish processing industry. Occup. Environ. Med. 1994, 51, 826-832. [CrossRef]

61. Bovenzi, M.; Zadini, A.; Franzinelli, A.; Borgogni, F. Occupational musculoskeletal disorders in the neck and upper limbs of forestry workers exposed to hand-arm vibration. Ergonomics 1991, 34, 547-562. [CrossRef] [PubMed]

62. Punnett, L.; Robins, J.M.; Wegman, D.H.; Keyserling, W.M. Soft tissue disorders in the upper limbs of female garment workers. Scand. J. Work Environ. Health 1985, 11, 417-425. [CrossRef] [PubMed]

63. Luopajärvi, T.; Kuorinka, I.; Virolainen, M.; Holmberg, M. Prevalence of tenosynovitis and other injuries of the upper extremities in repetitive work. Scand. J. Work Environ. Health 1979, 5, 48-55. [CrossRef] [PubMed]

64. Ohlander, J.; Keskin, M.C.; Weiler, S.; Stork, J.; Radon, K. Snap-fits and upper limb functional limitations in German automotive workers. Occup. Med. 2016, 66, 471-477. [CrossRef]

65. Taspinar, O.; Kepekci, M.; Ozaras, N.; Aydin, T.; Guler, M. Upper extremity problems in doner kebab masters. J. Phys. Ther. Sci. 2014, 26, 1433-1436. [CrossRef]

66. Ghosh, T.; Das, B.; Gangopadhyay, S. A comparative ergonomic study of work-related upper extremity musculoskeletal disorder among the unskilled and skilled surgical blacksmiths in West Bengal, India. Indian J. Occup. Environ. Med. 2011, 15, 127-132. [CrossRef]

67. Hembecker, P.K.; Reis, D.C.; Konrath, A.C.; Gontijo, L.; Merino, E.A. Investigation of musculoskeletal symptoms in a manufacturing company in Brazil: A cross-sectional study. Braz. J. Phys. Ther. 2017, 21, 175-183. [CrossRef]

68. Gold, J.E.; d'Errico, A.; Katz, J.N.; Gore, R.; Punnett, L. Specific and non-specific upper extremity musculoskeletal disorder syndromes in automobile manufacturing workers. Am. J. Ind. Med. 2009, 52, 124-132. [CrossRef]

69. Davis, K.G.; Kotowski, S.E. Prevalence of Musculoskeletal Disorders for Nurses in Hospitals, Long-Term Care Facilities, and Home Health Care: A Comprehensive Review. Hum. Factors 2015, 57, 754-792. [CrossRef]

70. Ohlsson, K.; Attewell, R.G.; Johnsson, B.; Ahlm, A.; Skerfving, S. An assessment of neck and upper extremity disorders by questionnaire and clinical examination. Ergonomics 1994, 37, 891-897. [CrossRef]

71. Descatha, A.; Leclerc, A.; Chastang, J.F.; Roquelaure, Y. Study Group on Repetitive Work. Medial epicondylitis in occupational settings: Prevalence, incidence and associated risk factors. J. Occup. Environ. Med. 2003, 45, 993-1001. [CrossRef] [PubMed]

72. Klussmann, A.; Gebhardt, H.; Liebers, F.; Rieger, M.A. Musculoskeletal symptoms of the upper extremities and the neck: A cross-sectional study on prevalence and symptom-predicting factors at visual display terminal (VDT) workstations. BMC Musculoskelet. Disord. 2008, 9, 96-103. [CrossRef] [PubMed]

73. Shiri, R.; Viikari-Juntura, E.; Varonen, H.; Heliövaara, M. Prevalence and determinants of lateral and medial epicondylitis: A population study. Am. J. Epidemiol. 2006, 164, 1065-1074. [CrossRef] [PubMed] 
74. Wolf, J.M.; Mountcastle, S.; Burks, R.; Sturdivant, R.X.; Owens, B.D. Epidemiology of lateral and medial epicondylitis in a military population. Mil. Med. 2010, 175, 336-339. [CrossRef] [PubMed]

75. Baumgard, S.H.; Schwartz, D.R. Percutaneous release of the epicondylar muscles for humeral epicondylitis. Am. J. Sports Med. 1982, 10, 233-236. [CrossRef]

76. Crouch, T. (Ed.) Obtaining an Accurate Diagnosis. In Carpal Tunnel Syndrome and Repetitive Stress Injuries: The Comprehensive Guide to Prevention, Treatment, and Recovery, 2nd ed.; North Atlantic Books: Berkeley, CA, USA, 1992; pp. 23-27.

77. Magnavita, N.; Elovainio, M.; De Nardis, I.; Heponiemi, T.; Bergamaschi, A. Environmental discomfort and musculo-skeletal disorders. Occup. Med. 2011, 61, 196-201. [CrossRef]

78. Magnavita, N. Work-related symptoms in indoor environments: A puzzling problem for the occupational physician. Int. Arch. Occup. Environ. Health 2015, 88, 185-196. [CrossRef]

79. Buckle, P. Upper limb disorders and work: The importance of physical and psychosocial factors. J. Psychosom. Res. 1997, 43, 17-25. [CrossRef]

80. Leino, P.I.; Hänninen, V. Psychosocial factors at work in relation to back and limb disorders. Scand. J. Work Environ. Health 1995, 21, 134-142. [CrossRef]

81. Bernard, C.; Bouée, S.; Adjémian, A.; Chrétien, J.C.; Niedhammer, I. Biomechanical and psychosocial work exposures and musculoskeletal symptoms among vineyard workers. J. Occup. Health 2011, 53, $297-311$. [CrossRef]

82. Wamper, K.E.; Sierevelt, I.N.; Poolman, R.W.; Bhandari, M.; Haverkamp, D. The Harris hip score: Do ceiling effects limit its usefulness in orthopedics? Acta Orthop. 2010, 81, 703-707. [CrossRef] [PubMed]

83. Feuerstein, M.; Nicholas, R.A.; Huang, G.D.; Dimberg, L.; Ali, D.; Rogers, H. Job stress management and ergonomic intervention for work-related upper extremity symptoms. Appl. Ergon. 2004, 35, 565-574. [CrossRef] [PubMed]

(C) 2020 by the authors. Licensee MDPI, Basel, Switzerland. This article is an open access article distributed under the terms and conditions of the Creative Commons Attribution (CC BY) license (http://creativecommons.org/licenses/by/4.0/). 